\title{
DESENVOLVENDO UM SIMULADOR EM ESCALA PARA ENSINO NA ÁREA NUCLEAR
}

Hudson Henrique da Silva - hudsonhenriquee@gmail.com

Universidade do Estado de Minas Gerais (UEMG)

Av. Paraná, 3001 - Jardim Belvedere I

35501-170 - Divinópolis - MG

Sincler Peixoto de Meireles - professorsincler@gmail.com

Universidade do Estado de Minas Gerais (UEMG)

Av. Paraná, 3001 - Jardim Belvedere I

35501-170 - Divinópolis - MG

Samira Santos da Silva - samirapgti@gmail.com

Universidade do Estado de Minas Gerais (UEMG)

Av. Paraná, 3001 - Jardim Belvedere I

35501-170 - Divinópolis - MG

Resumo: O modelo tradicional de ensino-aprendizagem por vezes dificulta com que o aluno compreenda como o conteúdo ensinado pode ser aplicado na prática. Sendo assim, abordagens mais recentes de ensino propõem a utilização do auxílio de ferramentas a fim de tornar o aprendizado uma tarefa mais prazerosa e engajadora. Este trabalho possui como objetivo a construção de um simulador do reator de pesquisa Triga IPR-R1 que está localizado no CDTN em Belo Horizonte, Brasil. Através do simulador, conceitos sobre reatores nucleares que antes seriam difíceis de explicar e de se compreender tornam-se possíveis.

Palavras-chave: Divulgação Científica. Reator Nuclear. Ensino. Simuladores

\section{INTRODUÇÃO}

O conhecimento traz autonomia ao ser humano, conectando-o com o ambiente, seus semelhantes e a si próprio (TAVARES, 2004). Ele é o que torna possível aprender e reconhecer outras ocasiões de conhecimentos semelhantes, permitindo agregar cada vez mais informação, que assim é transformada em mais conhecimento. O conhecimento se expande com a capacidade do ser humano de articular a informação que já conhece, junto à informação que se deseja aprender. Com isso, diversos trabalhos e pesquisas são realizados constantemente para que se encontre táticas de ensino que permitam otimizar o processo de aprendizagem, de forma que o aprendiz absorva o máximo de informações possíveis.

A aprendizagem pode ser compreendida como o processo de aquisição do conhecimento. O processo de ensino-aprendizagem pode ser divido em três modalidades: a educação escolar formal, que consiste no aprendizado do aluno no ambiente escolar; a educação informal, que é transmitida pelos pais, amigos, pela própria vivência em ambientes diferentes, e tudo que procede de atos espontâneos e naturais; e a educação não-formal, que seria quando se tem a intenção de obter o aprendizado estando fora do ambiente escolar (VIEIRA, 2005). Estes poderiam ser museus, feiras de ciências, oficinas, etc., cujo objetivo seria o de trazer ao visitante conhecimento mais palpável, que por muitas das vezes não pôde ser repassado pela 
instituição de ensino, até mesmo pelo fato de serem aplicados a cenários que não são acessíveis a pessoas leigas, devido por exemplo a riscos.

Os museus interativos têm muita relação com as métricas pedagógicas, podendo ser trabalhadas diversas estratégias para se ter um envolvimento intelectual dos usuários, buscando sempre maximizar o aprendizado do visitante. De acordo com Santos (2012), o objetivo do museu interativo é "dar às pessoas uma experiência viva e colocar o público em contato com as tecnologias atuais”. Entretanto, o museu interativo pode fazer mais que isso quando compreendido como espaço de divulgação científica e transmissão de conhecimento através de métodos não tradicionais.

Um dos principais recursos de museus interativos são os simuladores. Eles permitem com que o usuário tenha uma experiência mais realística do que ele representa sem necessariamente ter que se deslocar a ambientes que são de difícil acesso ou até mesmo manipular máquinas de grande tamanho e complexidade. Entretanto, simuladores são úteis não somente na divulgação de conhecimento em museus interativos, mas também no processo de ensino-aprendizagem em sala de aula. O modelo tradicional de ensino-aprendizagem traz consigo uma grande desvantagem: é difícil ao professor explicar a aplicabilidade de um conteúdo através de aulas expositivas e o aluno possui dificuldade em entender como o conteúdo ensinado pode ser aplicado na prática. Sendo assim, abordagens mais recentes de ensino propõem a utilização do auxílio de ferramentas e atividades interativas a fim de tornar o aprendizado uma tarefa mais prazerosa e engajadora.

Este trabalho possui como objetivo a construção de um simulador de um reator nuclear, especificamente de um reator de pesquisa Triga IPR-R1 que está localizado no Centro de Desenvolvimento de Tecnologia Nuclear (CDTN), em Belo Horizonte, Brasil. Atualmente, este reator é utilizado para pesquisas e estudos científicos ligados principalmente à irradiação de amostras para análise por ativação neutrônica. Através do simulador proposto, o usuário é capaz de perceber o quão simples e fácil é o processo de operação de um reator nuclear, sem a necessidade de acessar a sua versão real que se encontra em uma sala com acesso restrito no CDTN. No simulador, o usuário pode ligar o reator, controlar sua operação, podendo aumentar ou diminuir a carga de trabalho, e também simular um desligamento de emergência.

\section{TRABALHOS RELACIONADOS}

Inúmeros trabalhos vem sendo propostos com o objetivo de utilizar simuladores para o ensino e aprendizagem de diferentes conteúdos. Estes trabalhos ressaltam a importância que o aprendizado interativo dispõe principalmente quando implementados na transmissão de conhecimentos de difícil assimilação.

No trabalho de Heckler (2007), foi elaborado um material didático para o ensino de Óptica, área da física que estuda as leis associadas a radiações luminosas e fenômenos da visão (NEWTON, 2002). O material elaborado foi dirigido a professores e alunos do ensino médio, onde foram aplicadas algumas técnicas de aprendizagem recentes e tecnologias da informática que tornam o processo mais interessante aos olhos dos usuários. O trabalho foi desenvolvido em HTML, onde foram incluídos simuladores interativos, imagens estáticas e animações. Com isso, foi elaborado um CD-ROM com o material interativo. De acordo com 95\% dos alunos entrevistados, o material resultou em maior estímulo e interesse pelas aulas de física.

O trabalho de Barros (2012) traz a proposta da elaboração de um software simulador, denominado SimDeCS, que proporciona aos seus usuários a oportunidade de um aprendizado interativo. Ele traz a oportunidade do usuário (alunos de medicina e áreas relacionadas) simular procedimentos reais na área da saúde. A proposta desse simulador seria trazer casos 
clínicos complexos, onde o usuário poderia testar seus conhecimentos e serem avaliados no final, possibilitando a identificação de seus acertos e falhas. Outro objetivo desse simulador seria a possibilidade da redução do aprendizado apenas teórico, aproximando-se mais do aprendizado prático.

Em um outro trabalho, desenvolvido por Soares (2015), foi realizado um estudo da utilização de computadores e simuladores interativos para auxílio no aprendizado e compreensão de alguns fenômenos físicos na área da física moderna e contemporânea. A análise foi feita a partir das perspectivas sócio-interativas de Vygotsky, que em sua teoria propõe que é na interação entre pessoas que se constrói o conhecimento. Sendo assim, a proposta da utilização do computador e de simuladores interativos viria para viabilizar e potencializar a interação entre estudantes e professores. Em seu trabalho, foram abordados três temas diferentes relacionados a FMC (Física Moderna e Contemporânea): espectroscopia, radioatividade e física nuclear. $\mathrm{Na}$ abordagem de todos os temas, foram utilizados simuladores virtuais diferentes desenvolvidos pelo grupo PhET (Projeto de Simulações Interativas da Universidade de Colorado Boulder).

Por fim, o trabalho de Santos (2018) desenvolve um estudo sobre a utilização de um simulador em um espaço de aprendizagem com o objetivo de análise sobre a sua influência no aprendizado do aluno em temas da área de Ciência e Tecnologia, relacionados a processos científicos. Além disso, estuda a importância da utilização de ferramentas digitais de aprendizagem (simuladores e outras ferramentas de apoio), e da metodologia de ensino por investigação em casos envolvendo ferramentas digitais de aprendizagem. Esses estudos de casos seguiram uma metodologia de caráter qualitativo com alunos de duas turmas do $8^{\circ}$ ano escolar da Escola Básica de Santa Catarina da Serra.

Existem muitos simuladores na literatura, mas nenhum para o reator nuclear TRIGA IPRR1 que seja físico, ou seja, nenhum permite o contato real e palpável com um reator deste tipo. Além disso, os poucos simuladores físicos de reatores que existem possuem propósito de treinamento e não de divulgação científica. Por isso, faz-se necessário a elaboração de materiais e ferramentas que façam abordagens neste sentido. Principalmente, pelo fato de que sobre a área nuclear, a sociedade no geral possui pouco conhecimento e o pouco que sabem é sobre aspectos negativos, relacionados principalmente a acidentes, bombas ou até mesmo aos efeitos nocivos da radiação.

\section{METODOLOGIA}

Esta seção descreve a metodologia a ser utilizada na elaboração do simulador do reator TRIGA IPR-R1 proposto neste trabalho. A Seção 3.1 apresenta uma breve explanação sobre reatores nucleares. A Seção 3.2 aborda o estudo sobre a viabilidade da construção do simulador. A Seção 3.3 apresenta a definição e breve explicação sobre os componentes eletrônicos que serão utilizados neste trabalho. A Seção 3.4 traz os detalhes sobre a construção do simulador. Por fim, a Seção 3.5 descreve detalhes sobre a operação do simulador.

\subsection{Estudo sobre o Reator Triga IPR-R1}

Um Reator Nuclear é uma câmara de resfriamento hermética. É necessário que ela seja completamente blindada contra a radiação, pois no seu interior é onde ocorrem as fissões de núcleos de átomos de urânio de maneira controlada. Essas fissões liberam energia na forma de calor, quando então é utilizado um ciclo termodinâmico neste processo (BAITELO, 2007). Com o propósito de interromper as fissões no núcleo de um reator, são utilizadas barras 
(C) COBENCE

"Os desafios para formar hoje o engenheiro do amanhã"

metálicas de boro e cádmio que têm a propriedade de absorção de nêutrons (CARDOSO, 2012). Em um reator, essas barras são chamadas de Barras de Controle. O Elemento Combustível de um reator consiste em estruturas montadas que contém diversas varetas de combustível. Essas varetas são constituídas por uma liga especial de zircônio e podem suportar altas temperaturas (CARDOSO, 2012).

Reatores do tipo Triga são integrantes de uma classe de reatores de pequeno porte. Foram projetados com o principal objetivo de serem utilizados para pesquisa e formação de pessoal. O principal diferencial deste reator comparado aos demais é que ele não possui o risco de fusão do núcleo devido a excesso de temperatura, pois o seu elemento combustível é o UZrH (Urânio hidreto de zircônio), e a medida que a temperatura no núcleo sobe, os nêutrons liberados nas reações causam menos fissões no combustível (DE MEIRELES, 2018). Assim, tem-se que o próprio elemento combustível atua como um regulador automático da sua potência. Neste tipo de reator, o elemento combustível não é composto por estruturas montadas com varetas. As barras que contém as pastilhas são colocadas diretamente no reator. A Figura 1 retrata um recorte lateral do reator. Nesta figura, é possível notar os elementos combustíveis, as guias das barras de controle, o tubo central (TC) que é utilizado para que se possa levar amostras ao centro do núcleo, a fim de colocá-las expostas à radiação para análise em pesquisas, as placas inferiores e superiores, e os refletores de grafita (DE MEIRELES, 2018).

Figura 1 - Esquema do núcleo do reator Triga IPR-

R1.

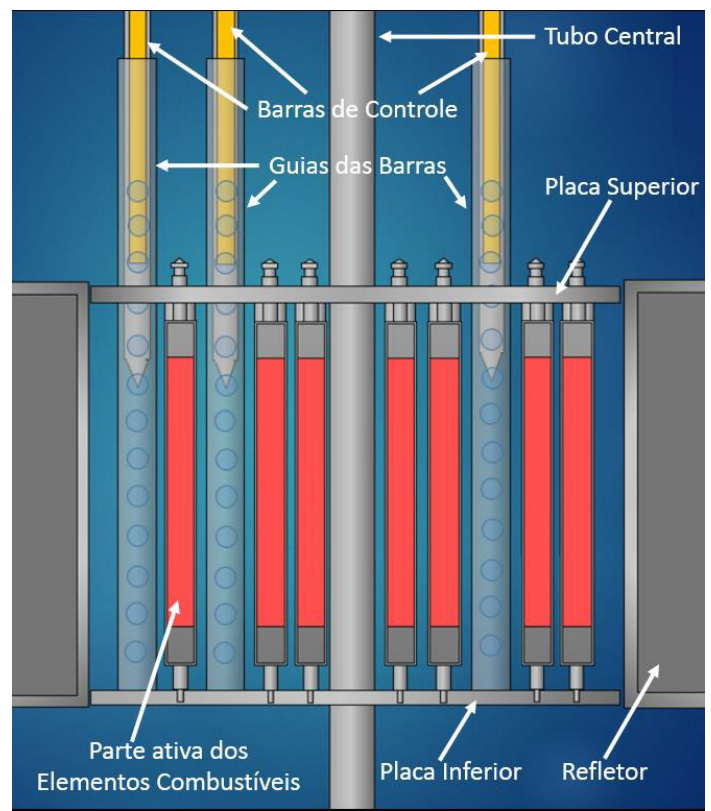

Fonte: De Meireles (2018)

\subsection{Estudo sobre Viabilidade da Construção do Simulador}

Inicialmente, foi realizado um estudo sobre a viabilidade da construção do reator. Nesta etapa, foram definidos tamanho e escala do reator para que, a partir disso, os componentes eletrônicos, como motores, resistores, CIs, dentre outros, pudessem ser dimensionados. Assim, o projeto do reator inicialmente foi definido escolhendo primeiramente o tamanho da tampa superior e inferior do simulador. Após isso, parte-se para a seleção do material que simularia o Elemento Combustível, o Tubo Central, e as Barras de Controle. Por fim, definiu- 
de materiais que seriam descartados no lixo ou em reciclagens, pois além de todos os objetivos já descritos nas seções anteriores, conseguir um simulador a baixo custo seria um ótimo benefício. O projeto elétrico montado no software Proteus é composto pela placa de prototipação Arduino, os três CIs 74HC595 que fazem a expansão das portas de saída do Arduino, os dois CIs 74HC165 que fazem a expansão das portas de entrada do Arduino, os três CIs L293D que fazem o gerenciamento e execução do funcionamento dos motores, os três motores de passo, os LEDs e Display que serão utilizados pelo usuário para acompanhar o funcionamento do simulador, além dos botões que transmitirão os comandos do usuário ao sistema para ser processado, e também alguns resistores que auxiliarão no funcionamento correto dos componentes.

\subsection{Operação do Simulador}

A manipulação do simulador de um reator, quando em cenário de testes ou simulação, pode ser realizada sem muitas dificuldades por qualquer pessoa de qualquer idade, devido a sua fácil operação. Como mencionado em seções anteriores, o grande motivo da manipulação do reator não ser tão simples em situações reais é o perigo que representa uma operação incorreta visto que os desastres causados podem trazer grandes prejuízos. Através do simulador, o usuário pode conhecer a operação de um reator real sem a ocorrência deste risco.

Ao dar inicio à operação do simulador, o usuário inicialmente deve ligar o gerador. Após isso, pode-se decidir descer quais barras de controle quiser, ou simplesmente desligar completamente o reator. É válido ressaltar que, para desligar o reator sem utilizar o modo de emergência, basta que quaisquer uma das duas barras de controle centrais estejam abaixadas, e com isso aos poucos o reator terá cada vez menos fissões, até parar por completo. Portanto, mesmo que o usuário não pressione o botão para desligar o reator, se o mesmo executar este procedimento acima, o reator desligará da mesma maneira. A seguir, a Figura 2 ilustra de maneira mais clara o processo de operação do simulador.

Figura 2 - Fluxograma de utilização do simulador do reator IPR-R1.

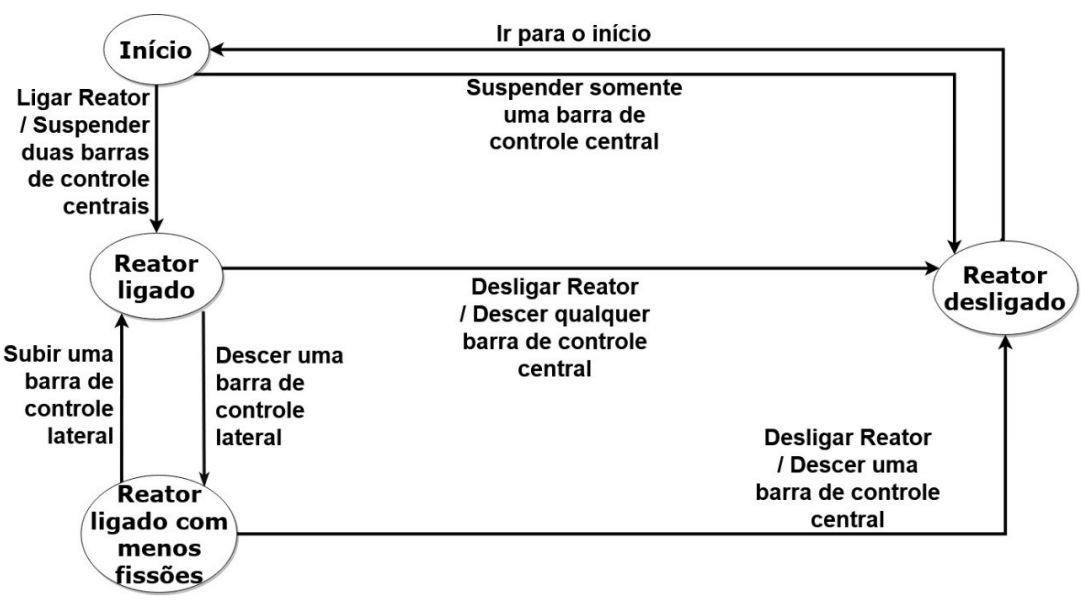

Fonte: Do Autor.

\section{RESULTADOS}

O principal item levado em consideração para que se pudesse definir a proporção que o simulador teria em relação à versão original existente no CDTN foi o denominado Elemento 
Combustível, visto que, na construção, esta peça se repete por 87 vezes, que é a quantidade de barras deste tipo existentes. Devido a isso, foi definido que a porcentagem de proporção seria de aproximadamente $44,57 \%$ em relação ao reator original, pois o Elemento Combustível no tamanho real possui a largura de $3,56 \mathrm{~cm}$ e o bastão de madeira utilizado para representar neste simulador tem $1,587 \mathrm{~cm}$. Com base nessa informação, todo o restante das peças foram dimensionadas se aproximando o máximo possível dessa proporção.

A construção do simulador se iniciou através da confecção das barras do Elemento Combustível, Barras de Controles e guias das barras. Em seguida, foi possível caminhar em direção à construção do núcleo do reator, onde seriam acomodados os elementos combustíveis, guias, barras de controle, tubo central e tampas superior e inferior. Após esta etapa, foi iniciada a construção da base de sustentação para o núcleo, onde foram utilizadas frações de madeira MDF, cilindros de cartuchos de impressora e diversos parafusos para facilitar a junção dos itens. A confecção do poço do reator e da ponte que sustenta os motores e barra de controle foi elaborada utilizando frações de madeira MDF e diversos parafusos.

A confecção da placa com o circuito planejado anteriormente foi feita utilizando uma placa de fenolite de tamanho $15 \mathrm{~cm}$ x $20 \mathrm{~cm}$. O desenho foi planejado inicialmente no software PCB Wizard, para que fosse realizada a melhor organização possível das trilhas e evitar ao máximo as interseções nas mesmas. Após o circuito planejado da placa, foi realizada a impressão do circuito planejado em papel de alto brilho utilizando uma impressora a laser, e então foi utilizado o método de transferência térmica para que o circuito fosse desenhado na placa de fenolite. Após o circuito ser transpassado para a placa, foi necessário deixar a placa em repouso na solução de Percloreto de Ferro, para que fosse feita a corrosão das partes necessárias e assim então resultasse no circuito desejado. Após este processo, realizou-se a limpeza das trilhas, a furação dos pontos necessários e a soldagem dos componentes e fios. A seguir, a Figura 3 exibe a placa na vista superior e inferior como resultado do processo descrito acima.

Figura 3 - Placa de circuitos do simulador do reator IPR-R1.

(a) Vista Superior

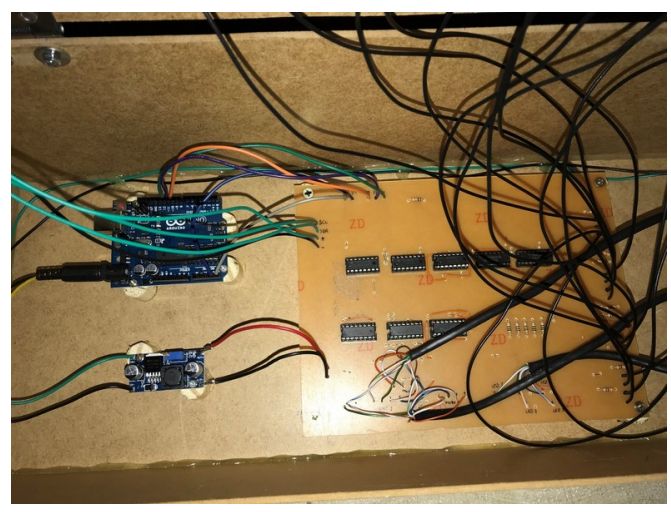

(b) Vista Inferior

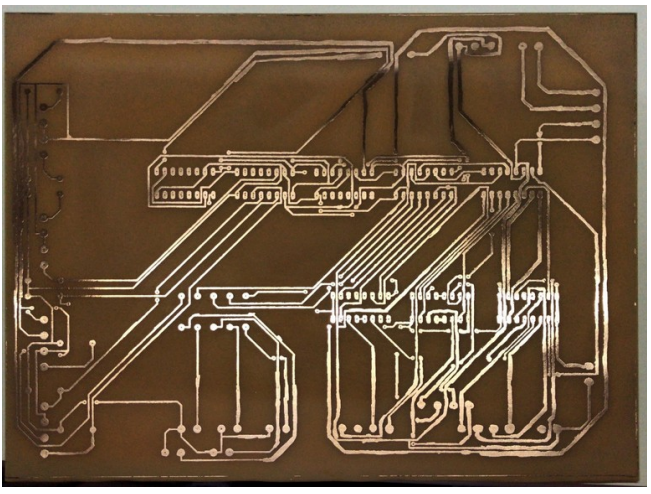

Fonte: Do Autor

Para permitir a interação do usuário com o simulador, foi elaborado um caixote de formato retangular que pudesse acomodar as placas que fazem o controle do reator, incluindo os botões de acionamento e display informativo. Este mesmo caixote simularia os controles encontrados no ambiente que em sua versão real é chamado de Sala de Controle. É neste ambiente que os operadores de reator fazem o controle do funcionamento do reator. Este 


\section{COBENCE de Educação em Engenharia da ABENGE}

"Os desafios para formar hoje o engenheiro do amanhã"

caixote foi confeccionado utilizando madeira MDF, adesivo termoplástico, alguns parafusos e dobradiças para fixação das partes. A Figura 4 ilustra toda a distribuição dos componentes e suas interligações internas.

Figura 4 - Caixa controladora do simulador do reator IPR-R1.

(a) Vista Exterior

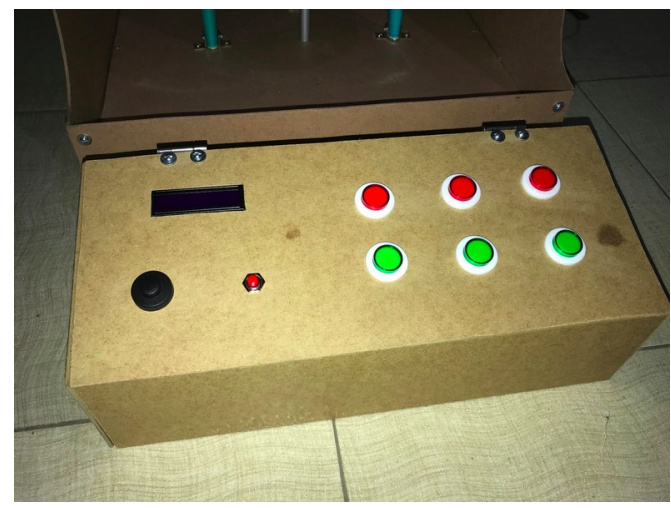

(b) Vista Interior

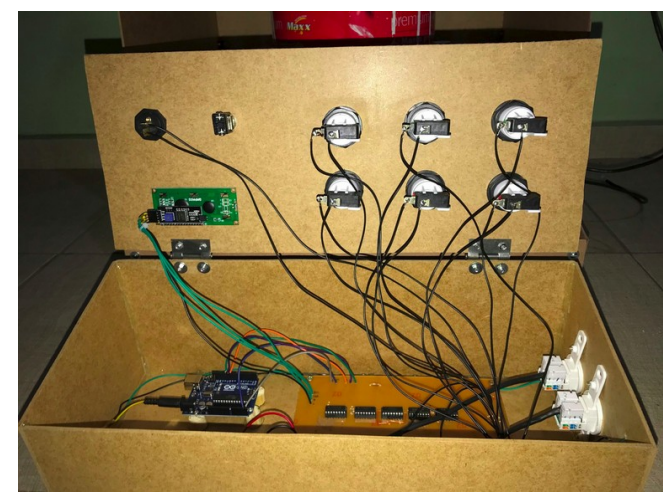

Fonte: Do Autor.

Então, foram instalados os motores de passo no topo da ponte e implementadas todas as conexões necessárias entre os motores e LEDs. Estes motores e LEDs foram fixados no simulador do reator, e para que fossem interligados com o restante do circuito que se encontra no caixote de controle, foram utilizados cabos com 8 vias, conhecidos popularmente como cabo de rede. Em suas pontas, foram utilizados conectores RJ45 para facilitar a inicialização do simulador sempre que se desejar utilizá-lo. Por fim, a Figura 5 (a) oferece uma visão ampliada do núcleo do simulador proposto e na Figura 5 (b) apresentamos a junção de todas as partes que irão trabalhar em conjunto e que compõem o simulador do Reator Triga IPR-R1 proposto.

Figura 5 - Simulador do reator Triga IPR-R1.

(a) Núcleo do simulador.

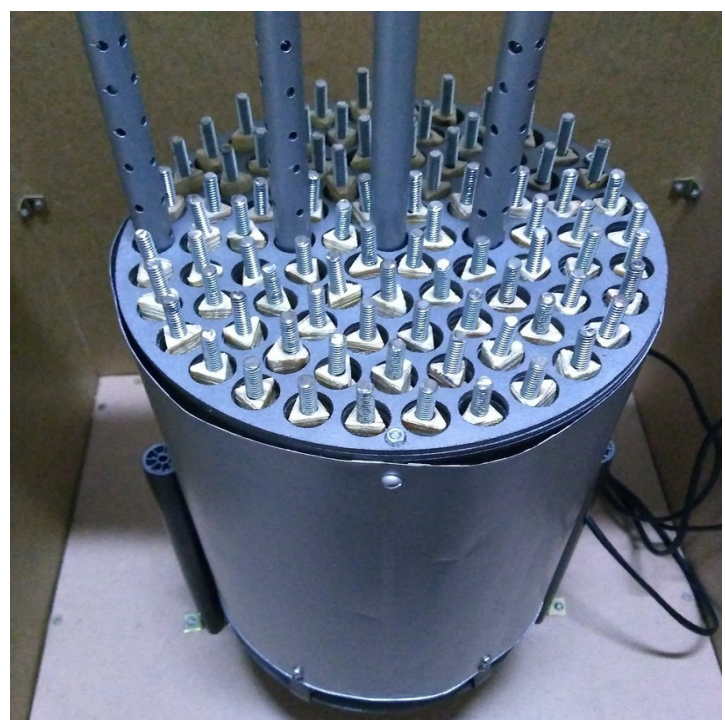

(b) Simulador completo.

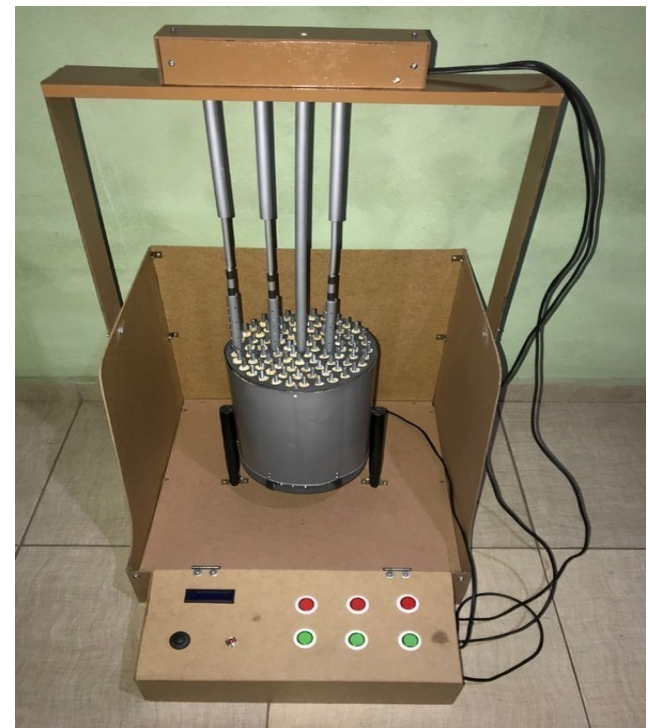

Fonte: Do Autor. 
O custo dos materiais utilizados na construção no simulador atingiu um valor satisfatório, principalmente quando consideramos que o mesmo permite a utilização e visualização da operação de um reator nuclear por mais de um usuário por vez. Algumas das principais desvantagens dos simuladores virtuais é o fato de permitirem a utilização por apenas um usuário por vez e a necessidade de equipamentos eletrônicos como um computador, celular ou até mesmo de um óculos de realidade aumentada, o que pode tornar alto o investimento financeiro para que se possa ter algo dedicado a este propósito.

\section{CONSIDERAÇÕES FINAIS}

A construção do simulador do reator nuclear IPR-R1 proposta neste trabalho possuiu como foco proporcionar uma ferramenta que desperte em seus usuários, sejam eles alunos do ensino fundamental, médio, superior ou até mesmo professores, a curiosidade e a capacidade investigativa necessárias para a compreensão de conceitos não somente de física mas também de química envolvidos em um reator. Com uma proposta simples e objetiva de um simulador, espera-se contribuir principalmente para o setor da educação, pois através do que foi abordado ao longo da descrição deste trabalho, é possível destacar a grande importância da prática de um aprendizado interativo exercido com alunos, como forma de fixação do conteúdo, e também de engajamento do aluno com temas relacionados.

Apesar das dificuldades encontradas ao longo da execução do trabalho, que demanda um pouco de conhecimento da área nuclear, considera-se que o planejamento e a construção do simulador do reator foram executados com êxito, resultando em uma versão que permite a simulação de condições de funcionamento bem próximas às condições reais do reator Triga IPR-R1. Através do simulador construído, será possível a pessoas leigas não somente a aproximação de uma versão bem próxima do reator real, mas também seu emprego no esclarecimento de conceitos e definições relacionadas às áreas de física e química e, principalmente da área nuclear, que seriam difíceis de explicar de forma teórica.

Em relação a possíveis trabalhos futuros, considera-se realizar a exposição do simulador construído em feiras de ciências e congressos, a fim de colher informações que possam validar o projeto construído sobre sua eficácia no processo de aprendizagem. Também considera-se fazer calibrações como forma de melhorias no simulador, onde seja possível movimentar as barras de controle parcialmente de modo a se aproximar cada vez mais do funcionamento real do reator Triga IPR-R1. A partir desse refinamento, ele pode não somente atender ao objetivo de divulgação de conhecimento científico e aprendizagem interativa, mas também pode servir como ferramenta de treinamento.

\section{REFERÊNCIAS}

BAITELO, Ricardo. Cortina de fumaça: as emissões de gases estufa e outros impactos da energia nuclear. São Paulo, Greenpeace, 2007.

BARROS, Paulo Ricardo Muniz et al. Um simulador de casos clínicos complexos no processo de aprendizagem em saúde. RENOTE-Revista Novas Tecnologias na Educação, v. 10, n. 1, 2012.

CARDOSO, Eliezer de Moura et al. Energia Nuclear. Apostila Educativa. Rio de Janeiro, 2012.

DE MEIRELES, Sincler Peixoto. Modelagem e cálculo de queima do reator triga ipr-r1 
"Os desafios para formar hoje o engenheiro do amanhã"

utilizando os códigos monpx e serpent. 2018. Tese (Doutorado) - Centro de Desenvolvimento da Tecnologia Nuclear, Belo Horizonte, 2018.

HECKLER, Valmir; SARAIVA, Maria de Fátima Oliveira; OLIVEIRA FILHO, Kepler de Souza. Uso de simuladores, imagens e animações como ferramentas auxiliares no ensino/aprendizagem de óptica. Revista Brasileira de Ensino de Física, v. 29, n. 2, p. 267273, 2007.

NEWTON, Isaac; ASSIS, André Koch Torres. Óptica. Edusp, 2002.

SANTOS, Rita Sofia Ramalho dos. O simulador Photolab num espaço de aprendizagem por investigação no desenvolvimento de competências do processo científico. 2018. Dissertação (Mestrado) - Escola Superior de Educação e Ciências Sociais do Instituto Politécnico de Leiria, Leiria, Portugal, 2018.

SANTOS, Thais Conde Dias. Museu interativo de vídeo jogos. 2012. Trabalho de Conclusão de Curso (Graduação em Design de Ambientes) - Universidade do Estado de Minas Gerais, Belo Horizonte, 2012.

SOARES, Antonio Augusto; MORAES, Letícia Estevão; OLIVEIRA, Franciéle Gonçalves. Ensino de matéria e radiação no ensino médio com o auxílio de simuladores interativos. Caderno Brasileiro de Ensino de Física, v. 32, n. 3, p. 915-933, 2015.

TAVARES, Romero. Aprendizagem significativa. Revista conceitos, v. 10, n. 55, 2004.

VIEIRA, Valéria; BIANCONI, M. Lucia; DIAS, Monique. Espaços não-formais de ensino e o currículo de ciências. Ciência e Cultura, v. 57, n. 4, p. 21-23, 2005.

\section{DEVELOPING A SIMULATOR IN SCALE FOR TEACHING IN THE NUCLEAR AREA}

Abstract: The traditional teaching-learning model sometimes makes it difficult for the student to understand how the taught content can be applied in practice. Therefore, more recent teaching approaches propose the use of tools in order to make learning a more enjoyable and engaging task. This work aims to build a simulator for the research reactor Triga IPR-R1 that is located at the CDTN in Belo Horizonte, Brazil. Through the simulator, concepts about nuclear reactors that previously would be difficult to explain and to understand become possible.

Keywords: Scientific divulgation. Nuclear reactor. Teaching. Simulators 